\title{
Uma Breve história da Biogeografia: De Linnaeus à Revolução Croizatiana
}

\author{
Valéria Gallo \\ Doutora em Geociências (USP), Professora Associada do Departamento de Zoologia (UERJ) \\ $\triangle$ galloval@gmail.com \\ Francisco José de Figueiredo \\ Doutor em Ciências Biológicas (UFRJ), Professor Associado do Departamento de Zoologia (UERJ) \\ 凹ffig@globo.com \\ Bruno Araujo Absolon \\ Doutor em Biociências (UERJ), Professor da Universidade Santa Úrsula \\ $\bowtie$ absolonbruno@gmail.com
}

Recebido em 14 de novembro de 2020

Aceito em 27 de abril de 2021

\section{Resumo:}

Com o objetivo de incrementar o ensino de disciplinas multifacetadas que lidam com aspectos dinâmicos das biotas no espaço, em curta ou longa escala temporal, é apresentada uma concisa história da biogeografia na fase pós-lineana, explorando aspectos interdisciplinares. Assume-se que, a partir da primeira formalização biogeográfica de Linnaeus, com o postulado centro de criação e dispersão, tiveram início as fases narrativa e analítica da biogeografia histórica. Descortinar descobertas, eventos e protagonistas permite uma revisão de conceitos que nortearam a história biogeográfica contemporânea. A abordagem, ainda não esgotada, contribui tanto para o aspecto ilustrativo disciplinar quanto para o desenvolvimento de senso crítico referente ao conteúdo. As ideias dispersionistas pós-lineanas de seletos naturalistas dos séculos XVIII e XIX são exploradas e contrastadas com a revolucionária proposta do botânico León Croizat. Sua inspiradora metáfora Terra e vida evoluíram em conjunto - representou uma ruptura epistemológica em relação ao dispersionismo clássico e influenciou a criação de novas escolas de pensamento biogeográfico, rivais ou complementares. Com a pan-biogeografia de Croizat, houve uma valorização da relação espaçotemporal dos componentes bióticos, dentro da tríade Space, Time and Form. Por outro lado, o paradigma da biogeografia insular, modelo dispersionista por excelência, longe de ser abandonado, revitalizouse recentemente com moderna abordagem.

Palavras-chave: Ensino de Biologia, Biogeografia, História, Pan-biogeografia, Dispersionismo, Vicariância.

\section{A Brief History of Biogeography: From Linnaeus to Croizatian Revolution}

\begin{abstract}
:
With the aim of increasing the teaching of multifaceted disciplines, that deal with dynamic features of biotas in geographical space, in a short or long time scale, a concise history of biogeography in the post-linnean phase is presented. We explore cases of interest for correlated areas of knowing. Linnaeus provided the first biogeographical formalization, with the postulate center of creation and dispersion, so that he is considered the starting point for narrative and analytical phases of the historical biogeography. Revealing discoveries, events and protagonists allows a revision of key concepts belonging to the mainstream of the contemporary historical biogeography. We think this approach, far from spent, contributes so to illustrate as well as to develop a critical perception
\end{abstract}


concerning content. The post-linnean dispersionist ideas of select naturalists from the 18th and 19th centuries are explored and confronted with the revolutionary proposal of the botanist Léon Croizat. His inspiring metaphor - earth and life evolved together - represented an epistemological rupture regarding the classical dispersionism and influenced the creation of new biogeographical thinking schools, rival or complementary. With the Croizat's panbiogeography, enhancing spatiotemporal relationships of biotic components prevailed within the triad - Space, Time and Form. On the other hand, the paradigm of island biogeography, a dispersionist model for excellence, far from being discarded, has recently been revitalized with a modern approach.

Keywords: Biology Teaching; Biogeography; History; Panbiogeography; Dispersionism; Vicariance.

\section{Una breve historia de la biogeografia: De Linneo a la Revolución de Croizat}

\section{Resumen:}

Con el fin de incrementar la docencia de materias polifacéticas que abordan aspectos dinámicos de las biotas en el espacio, a corto o largo plazo, se presenta una concisa historia de la biogeografía en la fase poslinneana, explorando aspectos interdisciplinarios. Se supone que, a partir de la primera formalización biogeográfica de Linnaeus, con el postulado centro de creación y dispersión, empezaron las fases narrativa y analítica de la biogeografia histórica. Revelar descubrimientos, hechos y protagonistas permite revisar los conceptos que guiaron la historia biogeográfica contemporánea. El planteamiento, aún no agotado, contribuye tanto al aspecto disciplinar ilustrativo como al desarrollo del sentido crítico sobre el contenido. Se exploran y contrastan las ideas poslinneanas dispersionistas de selectos naturalistas de los siglos XVIII y XIX con la propuesta revolucionaria del botánico León Croizat. Sua inspiradora metáfora - la Tierra y la vida evolucionaron juntas - representó una ruptura epistemológica con el dispersionismo clásico e influyó en la creación de nuevas escuelas de pensamiento biogeográfico, rivales o complementarias. Con la panbiogeografía de Croizat, hubo una apreciación de la relación espacio-temporal de los componentes bióticos, dentro de la tríada Space, Time and Form. Por otro lado, el paradigma de la biogeografía insular, modelo dispersionista por excelencia, lejos de ser abandonado, ha sido recientemente revitalizado con un enfoque moderno.

Palabras clave: Enseñanza de la Biología, Biogeografía, Historia, Panbiogeografía, Dispersionismo, Vicarianza.

\section{INTRODUÇÃo}

Desde o mais remoto tempo, o homem tem procurado compreender e explicar a presença de determinado organismo numa certa região, e, mais ainda, na sua distribuição em outras áreas.

A questão inicial perdura nos tempos atuais, através da pergunta "Como os organismos estão distribuídos na superfície terrestre e ao longo da história da Terra?", passando por diversas hipóteses de gregos, egípcios e árabes. A resposta se apoia no tripé forma, espaço e tempo, que também é o título de um importante livro do botânico italiano Léon Croizat "Space, time and form: the biological synthesis".

A Biogeografia é a ciência que aborda todas essas questões e pode ser definida como o estudo científico da distribuição geográfica dos organismos, incluindo os fatores históricos e 
evolutivos que a produziram, e os hábitats.

Neste artigo, é apresentada uma síntese das principais contribuições à Biogeografia, fornecidas por cientistas pós-lineanos do século XVIII, mas com abordagens bem similares, até a mudança de paradigma da segunda metade do século XX, com o método panbiogeográfico de Léon Croizat.

\section{A biogeografia dos séculos XVIII e XIX}

Adentrando na Biogeografia do século XVIII, cabe destaque inicial ao zoólogo alemão Eberhard Zimmermann (1743-1815) e sua obra Specimen zoologiae geographicae quadrupedum de 1777, na qual introduziu o termo "zoologia geográfica". Contribuiu, também, para a história da biogeografia, ao criticar a ideia de Linnaeus de um único evento de criação no tempo e no espaço. Ao contrário, Zimmermann sustentava que, se assim fosse, o primeiro casal de carnívoros X teria devorado o primeiro de herbívoros Y e assim por diante, causando uma verdadeira catástrofe ecológica. Para ele seria mais lógico pensar que Deus teria criado cada animal na área em que vive atualmente, a partir de grande quantidade de indivíduos e em condição de perfeito equilíbrio ecológico.

Karl Ludwig Willdenow (1765-1812), botânico alemão, defendia também que, ao invés da existência de uma ilha primordial única, como argumentava Linnaeus, a criação divina teria sido feita no topo de várias ilhas (ou montanhas), separadas pelo mar universal. A determinação das áreas de distribuição de plantas estaria ligada a estas montanhas originais (FIGUEIRÓ, 2015). Willdenow identificou várias dessas áreas, podendo ser considerada a primeira tentativa de divisão fitogeográfica do globo terrestre.

O naturalista francês Georges Louis Leclerc de Buffon (1707-1788) era contemporâneo e rival de Linnaeus (SLOAN, 2008). Acreditava que as espécies surgiam espontaneamente na natureza em algum ponto restrito, independente do seu grau de complexidade. Sua perspicaz observação que, em lugares diferentes da superfície terrestre com condições ecológicas similares, não ocorriam os mesmos táxons, originou a Lei de especiação geográfica e uma visão inicial de endemismo. Por outro lado, considerando que era etnocentrista, Buffon aplicou suas ideias tendenciosas em uma teoria holarticista para a história dos mamíferos. 
Estes teriam um centro de origem ou de criação no Hemisfério Norte, dispersando para outros locais com novas condições climáticas, tendo que se acostumar com distintos recursos alimentares.

Buffon, em sua obra Histoire naturelle (iniciada em 1749 e composta de 36 volumes), argumentava que Velho Mundo e Novo Mundo tiveram conexão no passado, possibilitando livre trânsito de animais. O mesmo teria acontecido com África e América do Sul. Já em "Épocas da Natureza" (BUFFON, 1812), considerado o primeiro grande corpo teórico para explicar mudança da forma no tempo e no espaço, Buffon postulou sete épocas de criação, tentando conciliar suas ideias científicas com as da teologia cristã, agradando a "gregos e troianos".

O alemão Alexander Von Humboldt (1769-1859), o Barão de Humboldt, teve uma preocupação maior com a quantificação dos fatores que se distribuem com a altitude. De maneira singular, demonstrou que há um paralelo entre sucessão altitudinal e latitudinal nas associações vegetais, ou seja, a distribuição das espécies de plantas, da base ao topo de uma montanha, ocorreria em zonas climáticas distintas (Figura 1).

Em releitura das cinco zonas climáticas de Parmênides, introduziu a ideia de associações vegetais com clima e outros fatores abióticos, que contribuiu muito para o desenvolvimento do conceito moderno de bioma (HUMBOLDT, 1817).

Figura 1. De Distributione Geographica plantarum, 1817. Detalhe da zonação da montanha com diferentes grupos de plantas.

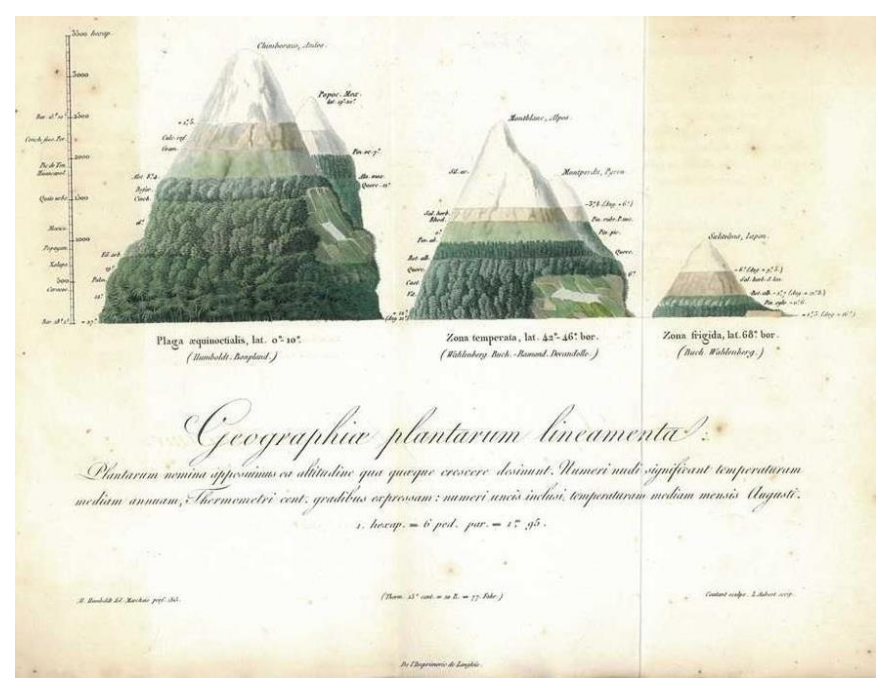

Fonte: Humboldt (1817). 
O botânico suíço Augustin Pyrame De Candolle (1778-1841) foi o primeiro autor a distinguir claramente os objetivos daquilo que, mais tarde, seria designado biogeografia ecológica e biogeografia histórica. Em sua Géographie Botanique, de 1820, considerou um estudo das estações para avaliar condições ambientais (e.g clima, altitude), que determinariam a permanência de uma espécie em uma determinada região. Por outro lado, indicou que havia um estudo alternativo, referente às causas históricas (origem, distribuição gradual, condições geográficas e geológicas, ou seja, aquelas que não mais existem no tempo atual), para explicar o aparecimento das espécies onde eram encontradas e seu grau de endemismo. Foi o que chamou de estudo das habitações (CANDOLLE, 1820). De forma pioneira, De Candolle dividiu a Terra em 20 províncias fitogeográficas (Figura 2) de acordo com o grau de endemismo e história dos diferentes grupos vegetais.

Figura 2. Regiões florísticas globais inspiradas em De Candolle

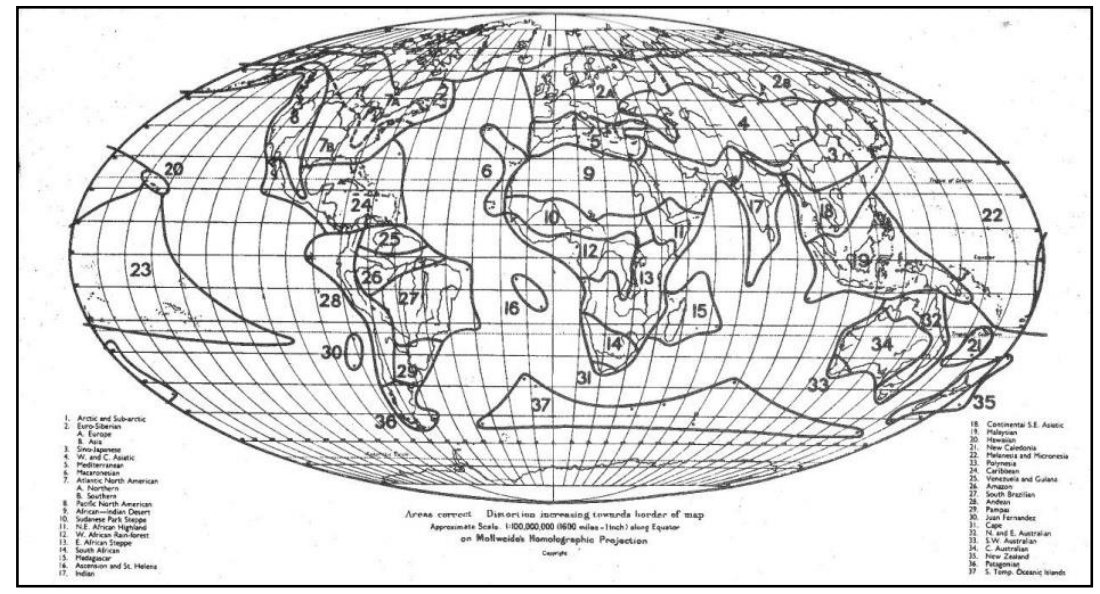

Fonte: (Good, 1964).

De Candolle criticou a ideia de degeneração ao longo do tempo e do espaço introduzida por Buffon. Defendeu causas históricas para o endemismo (como o tectonismo), argumentando que, mesmo tendo condições para vingar em lugares distantes com condições de clima e solo favoráveis, elas nunca ocorreriam lá em estado selvagem. Entretanto, apesar do brilhantismo dessas ideias.

O barão francês Georges Cuvier (1769-1832) pensava que as espécies eram permanentes e imutáveis. Postulou que, ao longo da história da Terra, ocorreram grandes catástrofes (o catastrofismo) com posterior renovação de fauna e flora. Esta renovação, na 
verdade, seriam novas criações divinas, que, para Cuvier, compreenderiam quatro grandes eventos. Mais tarde, o naturalista francês Alcide Dessalines D’Orbigny (1802-1857) refutou estes dados de Cuvier, afirmando terem ocorrido 27 eventos, com base na história geológica dos moluscos (D'ORBIGNY, 1850).

A maioria dos geólogos do século XIX e início do século XX acreditava que os continentes eram estáticos. O máximo que admitiam era a elevação ou abaixamento do nível do mar, possibilitando menor ou maior extensão continental. Alguns geólogos, rotulados de extensionistas, defendiam a hipótese de existência de antigas pontes de terra intercontinentais, então submersas, ideia do filósofo Platão. Outros, os permanenticistas, apostavam na chance e no potencial diferencial de cada espécie para dispersar. Portanto, a explicação de padrões biogeográficos por dispersão saltatória fazia total sentido no contexto de época: os organismos funcionariam como os componentes dinâmicos da paisagem, enquanto que o espaço geográfico seria praticamente estático ou permanente. Esta era a ideia de espaço absoluto, que perdurou por boa parte do século XX.

Pode-se dizer que a aceitação da ideia de espaço absoluto vingou, tendo em vista a ampla influência do geólogo britânico Charles Lyell (1797-1875). Em "Principles of Geology", estabeleceu as bases do uniformitarismo (BUENO \& LLORENTE, 2008), segundo o qual os processos que ocorrem no presente também ocorreram no passado, na mesma intensidade e no mesmo grau, sintetizado na famosa frase "o presente é a chave do passado". Uma reformulação do uniformitarismo foi denominada de atualismo e manteve a ideia básica de que os processos sucedidos no presente também atuaram no passado, mas podem ter variado em intensidade, grau e frequência. Lyell também rejeitou o modelo da ilha-montanha primordial de Linnaeus, uma vez que nunca se demonstrou a existência de um oceano universal e que, desde a primeira aparição de terra firme, ocorreram muitas substituições completas de plantas e animais, demonstrando-se cada vez mais o processo de extinção. As espécies surgiriam e se extinguiriam no tempo geológico paulatinamente. Lyell pensava que as mudanças ocorridas no tempo geológico eram via de regra graduais, lentas e contínuas. Em contraste com Cuvier, argumentava que não ocorreram períodos destacados de criação nem de extinção. As grandes mudanças seriam explicadas pelo acúmulo de mudanças pequenas; eventos repentinos e devastadores, como inundações e terremotos, seriam episódicos e de ação local. Para a biogeografia, Lyell sustentava que, como regra geral, haveria áreas com identidade biótica própria e que a dispersão ocorreria em casos excepcionais. No 
entanto, não houve um aporte sobre a existência das áreas de endemismo.

O geólogo norte americano James Dwight Dana (1813-1895) foi um dos pioneiros da Zoogeografia Marinha. Usou principalmente isotermas, coordenadas geográficas e variação das correntes marítimas para melhor estabelecer os limites das regiões ("províncias") e subregiões. Dividiu os oceanos em cinco grandes reinos: Americano (Ocidental), incluindo América ocidental e oriental; Afro-Europeu, costa da África ocidental e Europa; Oriental, incluindo as costas da África oriental, Índias orientais, Ásia oriental e meridional e Pacífico; Ártico e Antártico (DANA, 1879).

De real interesse para a história da Biogeografia no Brasil, destaca-se a contribuição de Emílio Joaquim da Silva Maia (1808-1859), que pode ser considerado o primeiro brasileiro a contribuir sobre o tema "Zoogeografia do Brasil" (FIGUEIREDO et al., 2017), com base nas ideias de Buffon e de Étienne Geoffroy Saint-Hilaire (SILVA MAIA, 1851). Silva Maia concordava com Humboldt que o número de espécies aumentaria dos pólos em direção aos trópicos. E, discordando de Buffon, Silva Maia não considerava os trópicos como área de degeneração de espécies. Muito pelo contrário, ele afirmou que:

\begin{abstract}
só ahi existem os que na escala animal possuem a organização mais complicada e as faculdades mais elevadas: nas regiões polares os animaes que apparecem são raros, e ordinariamente ocupam grau pouco alto na serie zoológica. Os macacos e elephantes entre os mammiferos, os papagaios e o condor entre as aves, os crocodilos e tartarugas entre os reptis, o mero e os voadores entre os peixes, animaes que são dos mais perfeitos, permitta-se-nos a expressão, nas suas respectivas classes, habitam as partes mais quentes dos dous continentes. (SILVA MAIA, 1852, p. 44).
\end{abstract}

Este relato mostra que Silva Maia era um defensor do Novo Mundo! Ele enfatizou que só nos trópicos encontramos "animais mais próximos ao homem", em termos de maior complexidade, e reafirmou a não degenerescência da fauna neotropical. 0 tema seria retomado, mais tarde, por Hermann Von Ihering, seu filho Rodolpho Von Ihering e Candido Firmino de Mello Leitão (MELLO LEITAO, 1947).

O zoológo inglês Phillip Lutley Sclater (1829-1913) dividiu a Terra em seis grandes regiões biogeográficas (Figura 3) reconhecendo padrões, com base na distribuição de grupos de aves (Sclater, 1858). Mas chamou a atenção para o fato de que o reconhecimento dessas divisões não era suficiente; seria importante uma tentativa de explicá-las. Dada três áreas, 
duas estariam mais relacionadas entre si do que com a terceira. Era a introdução do método comparativo na biogeografia, tal qual se verificaria em meados do século XX, na sistemática biológica. No entanto, o que se viu desde então foi uma preocupação maior com a delimitação e subdivisão de regiões pelos naturalistas, com base nos seus grupos taxonômicos de interesse.

As seis grandes regiões de Sclater foram incluídas em dois reinos zoogeográficos (“ornitogeográficos"): Creatio neogeana (regiões Neártica e Neotropical) e Creatio palaeogeana (regiões Paleártica, Etiópica, Indiana ou Oriental e Australiana). Além de estabelecer os limites entre estas regiões, indicou também a porcentagem de espécies endêmicas para cada uma delas.

Em 1897, Sclater propôs uma divisão dos oceanos também em seis grandes regiões, tendo como base a distribuição do leão marinho e focas: Arctatlantis, Mesatlantis, Indopelagia, Arctirenia, Mesirena e Notopelagia.

Figura 3. Regiões zoogeográficas de Phillip Sclater

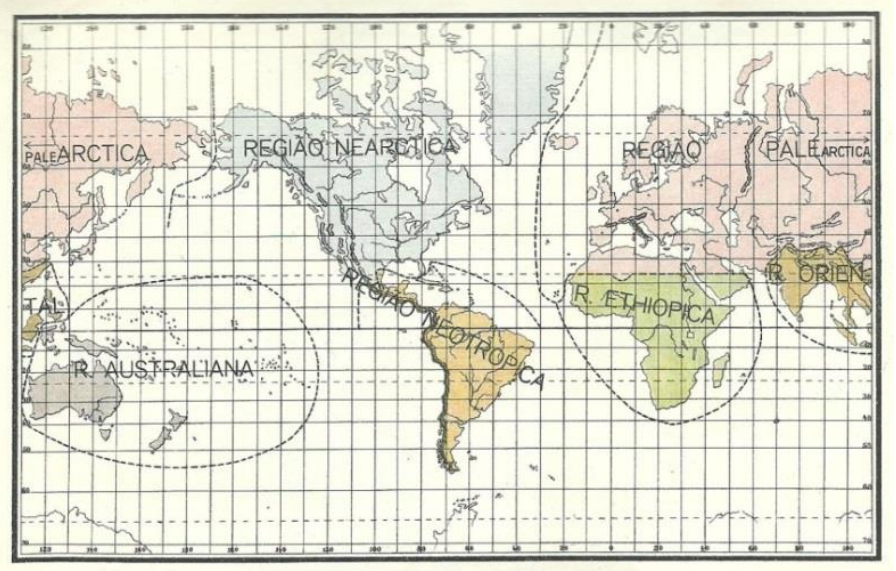

Fonte: Rodolpho Von Ihering (1939).

Alfred Russel Wallace (1823-1913) reuniu as informações até então disponíveis sobre a distribuição geográfica de vários animais, principalmente vertebrados terrestres, condensando-as em uma publicação de 1876 The geographical distribution of animals with a study of the relations of living and extinct faunas as elucidating the past changes of the earth's surfasse, que se tornou referência durante muitos anos e que continha sua proposta de classificação zoogeográfica. Nesta classificação, dividiu o mundo em seis regiões e 24 sub-regiões. Ele usava indistintamente similaridade e diferença, exclusividades de ocorrência e ausências como 
critérios válidos no reconhecimento destas regiões. Segundo Wallace, as espécies colonizariam novos hábitats e suas velhas fronteiras seriam divididas por montanhas e outras barreiras naturais, o que moldaria as áreas de distribuição atuais. Este mapa global de Wallace é tão importante que, apenas em 2013, foi feito um update dele por uma dezena de autores (HOLT et al., 2013). Neste artigo, são apontadas significativas diferenças entre o mapa de 1876 e o novo, mas com muitas similaridades, destacando o extraordinário trabalho realizado por Wallace.

Wallace era originalmente extensionista e acreditava que as áreas deveriam ser reconhecidas levando-se em consideração eventos do passado geológico. Fez algumas correções no modelo de Sclater, na tentativa de melhor fixar os limites (zonas de transição), e ainda propôs subdivisões. É famosa a sua tentativa de caracterização da zona de transição entre as regiões Oriental e Australiana, posteriormente denominada "Linha de Wallace", traçada entre Bali (região Oriental) e as ilhas Celebes e Lombok, na região Australiana (COX \& MOORE, 2009). Esta curiosamente é definida em função da presença de táxons que não podem ser atribuídos nem à região Oriental nem à Australiana e que apresenta características intermediárias, ou seja, sobreposição de elementos biogeográficos diferentes em associação com rarefação progressiva ao longo de gradientes opostos.

Curiosamente, Wallace antes da publicação de Origem das Espécies de Darwin, por várias vezes, indicou vicariância como fator relevante para a origem de novas espécies, ao promover disjunção de populações aparentadas que sofreriam divergência e diferenciação ao longo do tempo. A aceitação do darwinismo por parte de Wallace, por outro lado, condenou a biogeografia a explicações no cenário permanenticista, com a dispersão saltatória e aspectos ecológicos como carro-chefe.

Joseph Daton Hooker (1817-1911) utilizou uma combinação de dispersão e vicariância para explicar padrões de distribuição de plantas. Assim como Wallace, era extensionista, partidário das pontes de terra que ocorreriam em função de flutuações no nível do mar. Mesmo sendo amigo de Darwin, que era permanenticista, foi um dos pioneiros em apontar que hipóteses de vicariância são boas alternativas para as de dispersão. Há uma frase famosa e lúdica de Darwin, que ilustra muito bem essa divergência entre extensionistas versus permanenticistas (Figura 4). Darwin escreveu para Lyell: “... Se você não parar com isso, se houver uma região rebaixada para castigar geólogos, acredito eu meu grande mestre, que você acabará nela." 
A influência de De Candolle, Hooker, Sclater, Dana e Wallace foi marcante na história da biogeografia descritiva. Passou a ser comum a divisão e classificação da Terra em unidades biogeográficas. Houve proposta de aglutinação das seis grandes regiões em grandes reinos. Assim, alguns autores propuseram uma Lemurogeia (regiões Etiópica mais Oriental, com base no compartilhamento de vários grupos de prossímios), Arctogeia (também chamado Holártico, ou seja, Neártica mais Paleártica, com base na presença de ursos) e Didelfogeia (Neotropical mais Australiana, com base nos marsupiais). Outros autores arranjaram essas regiões em Notogeia (Australiana), Neogeia (Neotropical) e Arctogeia (resto do mundo).

Figura 4. Mapa mostrando várias pontes de terra transcontinentais, como era costume entre os extensionistas, segundo Hermann Von Ihering.

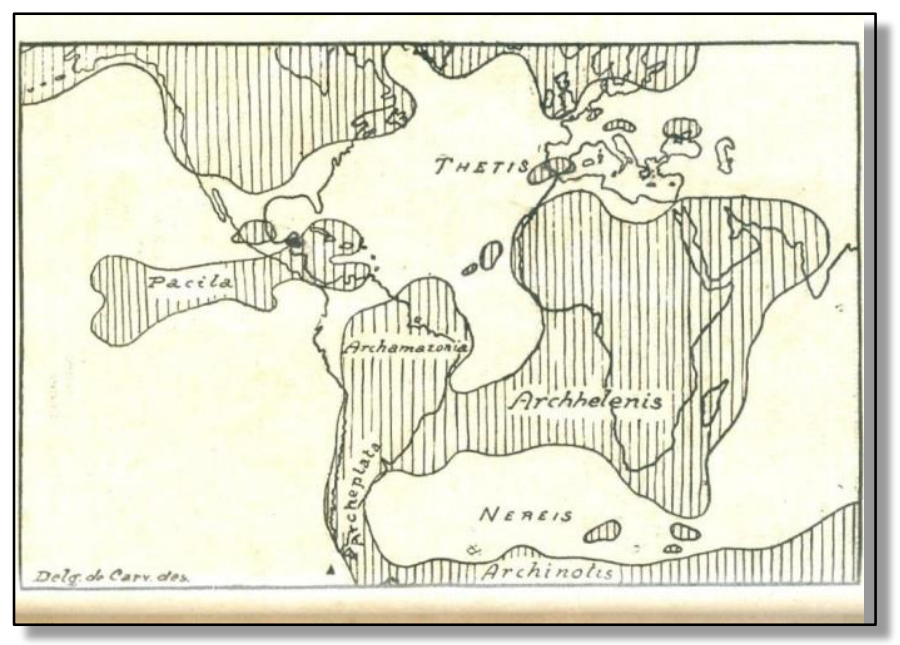

Fonte: Delgado de Carvalho (1913).

Para Charles Robert Darwin (1809-1882), permanenticista, as biotas seriam o resultado de convergência de histórias particulares (via dispersão) de táxons dentro de um contexto de espaço absoluto. O estudo biogeográfico residia na identificação de centros de origem e a proposição de uma rota de dispersão, com base em aspectos ecológicos e na capacidade de disseminação. A partir do centro de origem, gradualmente as espécies mais adaptadas deslocariam as menos adaptadas até o limite de distribuição do táxon. Para Darwin, ecologia seria a chave para desvendar padrões biogeográficos e os fósseis seriam essenciais no reconhecimento da rota de dispersão.

Muito antes da publicação de Origem das Espécies, já existiam explicações pioneiras para a formação de novas espécies via isolamento geográfico e que, certamente, inspiraram 
Darwin e Wallace. Talvez a mais antiga e contundente explicação tenha sido a do paleontólogo norueguês Christian Leopold von Buch (1774-1853), que em Physikalische Beschreibung des Canarischen, seu livro de 1825 sobre a fauna e a flora das Ilhas Canárias (CRUZ, 2016), descreveu sucintamente o processo de especiação geográfica:

Os indivíduos de um gênero se expandem sobre os continentes, se deslocam até lugares distantes, formam variedades (segundo as diferenças das localidades no alimento e no solo) que, devido a sua segregação (isolamento geográfico) não podem cruzar-se com outras variedades e deste modo retornar ao tipo principal original. Finalmente, estas variedades se tornam constantes e se transformam em espécies distintas. Posteriormente, podem tornar a alcançar o limite de outras variedades que se transformaram de forma análoga e as duas não se cruzam e se comportam como duas espécies verdadeiras diferentes (BUCH, 1825, p.150).

Mais tarde, em 1868, Moritz Friederich Wagner (1813-1887) chegou a conclusões similares e denominou de vicariantes duas espécies intimamente relacionadas e distribuídas em áreas geográficas disjuntas. Ele descreveu:

uma espécie incipiente surgirá quando uns poucos indivíduos transgredirem os limites de sua área de distribuição" e "a formação de uma nova raça nunca acontecerá sem uma longa e contínua separação dos colonizadores em relação a outros membros da espécie (WAGNER, 1850, p.130).

\section{DESENVOLVIMENTO}

\section{A Biogeografia dispersionista no século XIX}

As ideias de Darwin e Wallace inspiraram o desenvolvimento da escola de biogeografia histórica dispersionista, tendo como base centro de origem e dispersão saltatória (Figura 5). O dispersionismo pode ser sintetizado em cinco princípios: 1 - Os táxons surgem em áreas restritas da superfície terrestre (centro de origem), a partir da qual ocorre especiação subsequente; 2 - O centro de origem pode ser estimado de acordo com critérios específicos; 3 - Dentro do ponto de vista darwinista, as espécies novas evoluem e se dispersam, deslocando as mais primitivas para a periferia do centro de origem, de forma que os táxons mais modernos se encontram mais próximos do centro de origem e os mais antigos distantes do mesmo; 4 - Os animais e as plantas conseguem atingir áreas mais distantes por dispersão, em função de suas capacidades individuais; e 5 - O registro fossilífero é imprescindível para o esclarecimento da história no tempo e no espaço, de forma que os fósseis mais antigos estão 
próximos do centro de origem.

Deve-se levar em conta que o fenômeno da dispersão, ou translocação geográfica, pode ser abordado em diferentes níveis de generalidade, com significados biológicos distintos: (a) dispersão organísmica relativa aos mecanismos intrínsecos que permitem o espalhamento de um organismo em dada área, devido a adaptações particulares; (b) dispersão específica - expansão da área de distribuição, influenciada por eventos históricos de grande escala espacial (e.g, flutuações eustáticas, mudanças climáticas globais, tectônicas de placas; (c) dispersão biótica - transposição de barreiras preexistentes pela biota ou por alguns de seus elementos.

Figura 5. Centro de origem e rota de dispersão das antas no tempo geológico

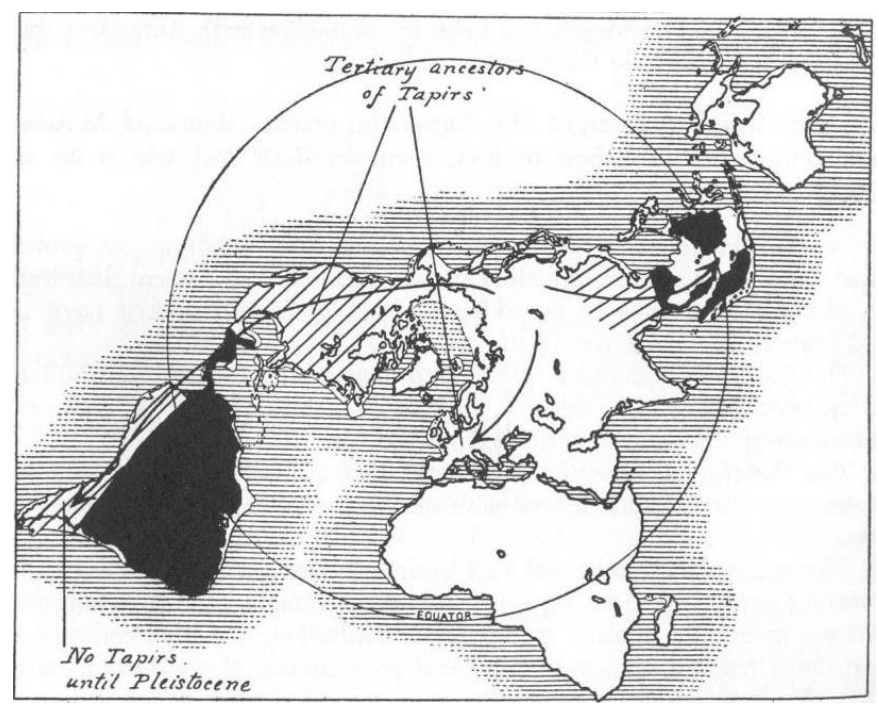

Fonte: Matthew (1915).

Tendo em vista que dispersão é sempre uma realidade no nível de organismo, os biogeógrafos dispersionistas extrapolaram, postulando rotas de dispersão intercontinentais e transoceânicas para as espécies recentes e extintas, com início sempre no centro de origem (Figura 6). Mas, um grande problema é que vários critérios, muitas vezes contraditórios, foram usados na sua determinação, entre eles: Área de maior diversidade taxonômica e ecológica; Área de maior abundância de indivíduos; Local onde se encontra a espécie mais recente do grupo (método darwinista); Local onde se encontram os fósseis mais antigos do grupo; Local onde se encontram indivíduos de maior tamanho; Direção indicada por rotas de migração anuais (para aves migratórias); Continuidade e direção de clinas (variações graduais 
de um caráter no espaço geográfico); Área na qual se encontra o táxon mais basal ou primitivo (método de Hennig) (HENNIG, 1968).

O zoólogo italiano Danielle Rosa (1857-1944) formalizou, depois de Darwin, uma teoria coerente e alternativa de evolução orgânica - a teoria da Hologênese (Rosa, 1931). Assumia que a evolução era determinada por causas internas e que se espelhava na divisão dicotômica que ocorre no desenvolvimento do embrião. Esta era refletida numa assimétrica relação filogenética, com ramo retardado e avançado da dicotomia envolvendo ancestral e seus descendentes. As causas internas poderiam ser hoje explicadas por mecanismos determinados geneticamente pelo kit herdado com todas as restrições e potencialidades para a mudança morfológica. Rosa postulava que na história geográfica de uma espécie, ao invés da assumir que a espécie ancestral surgiria num pequeno ponto da superfície terrestre, ela teria distribuição cosmopolita. A partir de então, os descendentes passariam a ocorrer em áreas cada vez menores, numa história moldada por dispersão e eventos geológicos. Suas ideias influenciariam mais tarde a formalização de propostas revolucionárias para a sistemática biológica (com Willi Hennig e seu cladismo) e para a biogeografia histórica (com Léon Croizat e sua Pan-biogeografia) (CROIZAT, 1978).

O paleomastozoólogo norte americano George Gaylord Simpson (1902-1984), um dos dispersionistas mais famosos, reconheceu três tipos de rotas de dispersão para grupos de espécies, com base no grau de similaridade faunística: (a) corredor: condições ecológicas de cada extremidade da área de distribuição seriam similares, favorecendo o livre fluxo ao longo dessa área, o que contribuiria para uma alta similaridade (maior homogeneidade); (b) filtro: a mescla de condições ecológicas favoráveis e desfavoráveis restringiria o livre fluxo e somente formas bem adaptadas teriam condições de alcançar os extremos, contribuindo para uma baixa similaridade, como por exemplo, o istmo do Panamá e o Saara; (c) páreo (sweepstake route): a distância e as condições ecológicas nas regiões intermediárias seriam muitos restritivas, de modo que a chance de cruzar a(s) barreiras (s) seria muito pequena (SIMPSON, 1940; 1965).

Aos poucos, vários problemas foram detectados com o dispersionismo: Se toda disjunção é explicada por dispersão, então padrões biogeográficos vicariantes nunca serão descobertos; Biota é resultante somente do somatório de potencialidades de dispersão em larga escala de linhagens individuais; Vários critérios, muitas vezes contraditórios, para se 
determinar o centro de origem; Biogeografia do vácuo: admite-se que podem existir áreas inicialmente mais vazias de fauna e flora; e falta de predizibilidade, já que se baseiam em narrativas para a história biogeográfica de cada grupo taxonômico.

Apesar dos problemas apontados acima, o dispersionismo perdurou e foi refinado dentro do contexto da biogeografia ecológica, no final da década de 1960, com o modelo quantitativo de Biogeografia de Ilhas, iniciada por Robert H. MacArthur (1930-1972) e Edward O. Wilson (1929-) (MACATHUR \& WILSON, 1967). Cabe ressaltar, entretanto, que certas e interessantes deduções iniciais sobre Biogeografia Insular podem ser atribuídas ao botânico alemão Johann Reinhold Forster (1729-1798). Segundo Forster, as ilhas abrigariam menos espécies vegetais que o continente e, por outro lado, o número de espécies nas ilhas aumentaria de acordo com os recursos disponíveis. De Candolle acrescentou a essas observações de Forster sobre floras insulares que a diversidade florística estaria relacionada, não só a fatores ecológicos, como clima e insolação, mas também a fatores históricos, como a idade da ilha e vulcanismo.

Segundo a Teoria da Biogeografia de Ilhas de MacArthur e Wilson, também denominada Teoria do Equilíbrio Biogeográfico Insular, a colonização de ilhas segue uma curva similar àquela do crescimento de uma população, daí a grande relação com a teoria da biologia populacional. A composição está em um constante estado de fluxo e a quantidade de espécies nas ilhas é menor que as das áreas continentais mais próximas. Em dado tempo, pode haver expressiva reposição com alta porcentagem de extinção por emigração balanceada pela imigração. A quantidade de espécies no equilíbrio permanece constante. Os autores desenvolveram métodos matemáticos para explicar este problema ecológico fundamental da regulação da diversidade. A princípio, esta teoria foi muito aceita, especialmente pelos ecólogos, porém vários problemas e críticas foram surgindo na aplicação da mesma. Um dos mais simples refere-se ao fato de que as biotas insulares podem não ter equilíbrio entre as taxas de imigração e extinção, simplesmente porque a diminuição ou o aumento da diversidade podem ser uma resposta a fatores evolutivos ou a eventos geológicos. A identidade e as características biológicas das espécies, como, por exemplo, reprodução e nível trófico não podem ser desconsideradas. Além disso, as trocas genéticas são potencialmente reduzidas em ilhas, logo o isolamento favorece especiação. Outra questão importante com relação ao equilíbrio insular refere-se às dimensões da área, ou seja, quanto maior a ilha, maiores seriam as chances de dispersão e colonização. Na realidade, o risco de extinção está 
mais relacionado com a diminuição do tamanho da população, considerando, por exemplo, qualidade do hábitat, competição interespecífica e relações tróficas. Além disso, as espécies respondem de forma distinta às velocidades de colonização e de extinção, que também podem ocorrer de modo estocástico. E, por fim, a escassez de estudos sistemáticos para uma correta identificação dos táxons dificulta a compreensão da origem da biota, se por especiação ou por imigração.

Todos esses questionamentos levaram a uma profunda revisão da Teoria da Biogeografia de Ilhas, nos anos 2000, a ponto de questões históricas serem incorporadas a ela, e sua nova versão está contida nos livros de Robert J. Whittaker e José Maria FernandézPalacios, de 2007, Island Biogeography: Ecology, Evolution, and Conservation, e Jonathan Losos e Robert E. Ricklefs, de 2009, The Theory of Island Biogeography Revisited. Seguindo nessa linha, mais recentemente, em 2014, foi produzida a publicação virtual Island Biology, com diversos artigos apresentando os recentes avanços na Biogeografia de Ilhas e tópicos de grande interesse atual no tema, dentre eles, as redes ecológicas reconhecidas em ilhas, os padrões macroecológicos de riqueza de espécies, estrutura biogeográfica e evolutiva em arquipélagos, reconstruções em longo prazo de ambientes insulares e como suas dinâmicas interagem com a sua biogeografia evolutiva. Estes estudos foram conduzidos em alguns dos arquipélagos mais pesquisados no mundo, como Hawaii, Galápagos, Macaronésia, Wallacea e Índias Ocidentais.

Um dos grandes impulsos para a biogeografia moderna foi à aceitação da teoria de deriva continental por tectônica de placas. Já nos tempos de Darwin, o padre francês Antonio Snider-Pellegrini (1802-1885), em 1858, reuniu evidências geológicas e paleontológicas para sustentar a ideia de separação dos continentes, observando a semelhança entre a flora de camadas de carvão de 300 milhões de anos dos Estados Unidos e Europa (SNIDER-PELLEGRINI, 1858; TOMECEK, 2009). Ele foi pioneiro em figurar condição pré- e pós-separação, apresentando o primeiro diagrama com a reconstituição dos continentes (Figura 6).

Somente no início do século XX, a ideia seria trabalhada de novo, com mais evidências, por Frank Bursay Taylor (1860-1938), nos Estados Unidos, e Alfred Wegener (1880-1930), na Alemanha. 
Figura 6. Primeira ilustração da deriva de continentes
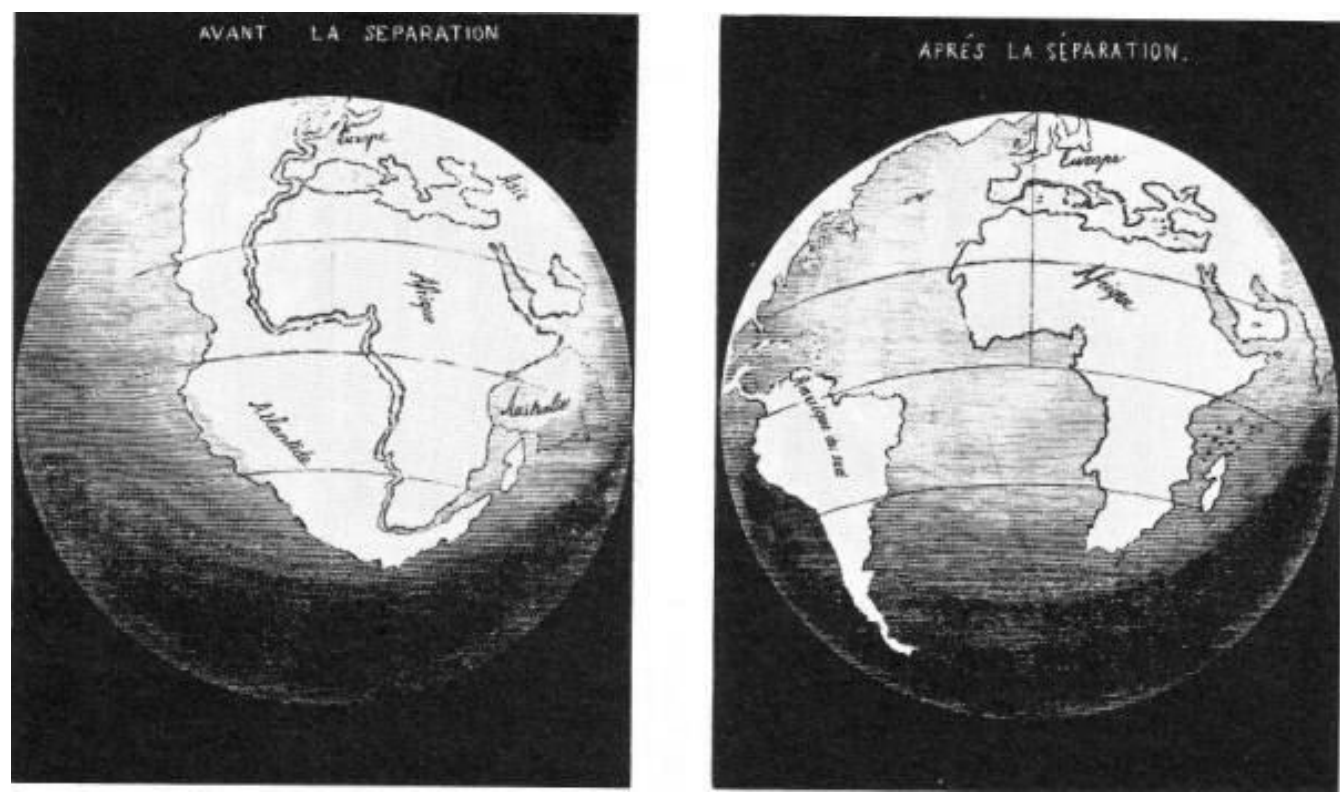

Fonte: Snider-Pellegrini (1858).

\section{A Revolução Biogeográfica de Léon Croizat}

No final da década de 1940, Léon Camille Marius Croizat (1894-1982), botânico italiano, desenvolveu teoria e metodologia, intitulada Pan-biogeografia, para a recuperação de padrões biogeográficos replicados (traços generalizados) por elementos de biotas, explicando-os de forma coerente segundo processos históricos subjacentes. Nesse contexto, ele resgatou o conceito de vicariância (vicarius, aquele que substitui outro no local; -antia, sufixo que denota ação e efeito) como uma alternativa para a dispersão através de barreiras preexistentes. Na verdade, este e a expansão dos limites seriam os processos biogeográficos a serem considerados na distribuição dos grupos. Argumentava que com a vicariância a barreira é da mesma idade dos grupos de organismos separados por ela, sendo um evento comum aos elementos de uma biota e o processo causal da diversidade. Portanto, hipóteses com base em vicariância seriam testáveis, enquanto que aquelas baseadas em dispersão saltatória (aleatória, evento particular), não. A dispersão admitida por Croizat é a hoje denominada geodispersão, que se refere à expansão da distribuição dos táxons em resposta à remoção de uma barreira.

Para Croizat, a evolução seria constituída de três componentes: espaço, tempo e forma. Por forma (do inglês, form), subentende-se todo e qualquer atributo intrínseco de um 
organismo (i.e., morfologia, fisiologia, comportamento), capaz de sofrer transformação ao longo do tempo. Em contrapartida, as áreas onde esses organismos são encontrados também se transformam. As mudanças nos atributos e as áreas que abrigam organismos estão interligadas. Para ele, Terra e sua grande biota evoluíram em conjunto ("Earth and life evolve together"), em regime de intervenção recíproca. Dessa forma, o conceito de espaço para Croizat era muito diferente daquele assumido por Darwin e seguidores. Para Croizat, espaço seria uma propriedade da matéria: quando altera o espaço, muda a matéria. É a ideia de espaço relativo. Com a introdução deste conceito em biogeografia, Croizat pôs em xeque a hipótese corrente para sua época de uma Terra cuja história seria independente daquela dos seres vivos. Entretanto, embora seja uma bela metáfora, Morrone (2015) questinou-a, uma vez que as relações entre as histórias da Terra e da vida são mais complexas, nem sempre correndo em paralelo, podendo ser também reticuladas.

Embora Croizat tenha defendido a ideia de um espaço não estático, sua obra é inconclusiva sobre se aceitava ou descartava a tectônica de placas para explicar o padrão de distribuição dos organismos (GREHAN, 1984; MORRONE, 2000). Na verdade, em muitos dos seus trabalhos iniciais, Croizat foi contra o Wegenerismo. Ao contrário de continentes e oceanos móveis, defendia que subidas e descidas dos fundos oceânicos foram as causas da mudança na distribuição das massas de terra ao longo do tempo geológico. Ele manteve suas localidades fixas e propôs pontes continentais e oceânicas efêmeras para explicar a maior parte das conexões entre as disjunções, tais como as dos continentes do Hemisfério Sul.

A relevância das ideias de Léon Croizat está para a Biogeografia, assim como as do entomólogo alemão Willi Hennig (1913-1976) está para a sistemática biológica. Croizat libertou a biogeografia do ranço dispersionista, enquanto Hennig libertou a sistemática da busca por "elos perdidos". A integração das ideias de Croizat com as de Hennig teria contribuído para o desenvolvimento de uma biogeografia histórica com forte metodologia explícita.

O método pan-biogeográfico foi desenvolvido por Croizat (1958) e constava da análise de traços, realizada de modo não quantitativo. Por esta razão e, provavelmente pelo seu comportamento idiossincrásico, o método não foi muito aceito e utilizado pela comunidade científica. Além disso, COX (1998) considerou que dois fatores impediram as ideias de Croizat: sua rejeição extrema da dispersão casual como um possível mecanismo em qualquer 
circunstância e sua terminologia particular, que diferia daquela utilizada em outras abordagens biogeográficas. GREHAN (2001) rebateu COX (1998), afirmando que Croizat nunca rejeitou a dispersão e que sua terminologia particular refletia um quadro conceitual completamente diferente do dispersionismo e da biogeografia cladística. Grehan esclareceu ainda que o método pan-biogeográfico não pretendia discutir, num primeiro momento, os conceitos de dispersão e vicariância. Na verdade, a ideia era comparar vários mapas de distribuição de diferentes grupos, ou seja, um método basicamente gráfico. Croizat reconheceu padrões compartilhados de dispersão e propôs um "modo de dispersão de forma vicariante geral", no qual "centro de endemismo seria representado pela combinação de todos os membros vicariantes de um táxon". Croizat acrescentou ainda que a vicariância deveria ser a primeira hipótese explanatória e a mais abrangente, e a dispersão ser atribuída a casos particulares.

Apenas nos anos 1980, com o interesse por parte dos biogeógrafos neozelandeses, a metodologia de Croizat foi revista e expandida, sendo incorporados métodos matemáticos a ela, como a análise de traços (CROIZAT, 1958, 1964) árvores de distância mínima e método de compatibilidade de traços (e.g., PAGE, 1987; CRAW et al., 1999). A necessidade de quantificar a genuína Pan-biogeografia pode ser resumida no jogo de palavras de Daniel Rafael MirandaEsquivel e Susy Echeverría-Londoño "Analyses and software have to evolve together", a partir da famosa e já referida metáfora de Croizat "Earth and life evolve together".

Dos métodos quantitativos acima mencionados, o método pan-biogeográfico de análise de traços é o mais utilizado e consiste em marcar localidades de ocorrência de táxons em mapas, ou seja, suas coordenadas geográficas, e conectá-las mediante linhas de menor distância, por sua proximidade geográfica, que são denominadas traços individuais. Estes correspondem às áreas de distribuição do táxon e o local onde ocorreu sua evolução.

A superposição de traços individuais corresponde a um traço generalizado, o qual representa o padrão atual de distribuições de biotas ancestrais mais extensas no passado, fragmentadas por eventos físicos ou geológicos. A região de convergência de traços generalizados é denominada nó biogeográfico, o qual sugere, dentro de um contexto geológico moderno, áreas híbridas (compostas) ou de fusão de placas tectônicas. Na verdade, estes são os denominados por alguns autores nós generalizados, uma vez que existe também uma definição de nós individuais, formados pela interseção de dois ou mais traços individuais, 
representando o limite entre duas espécies-irmãs (HEADS, 2004; MORRONE, 2011; 2015) (Figura 7).

Figura 7. Mapa-múndi mostrando, segundo método manual pan-biogeográfico, traços generalizados com as relações históricas entre diferentes biotas de áreas continentais. Nós biogeográficos (áreas complexas indicadas pela convergência de traços) aparecem como círculos amarelos numerados.

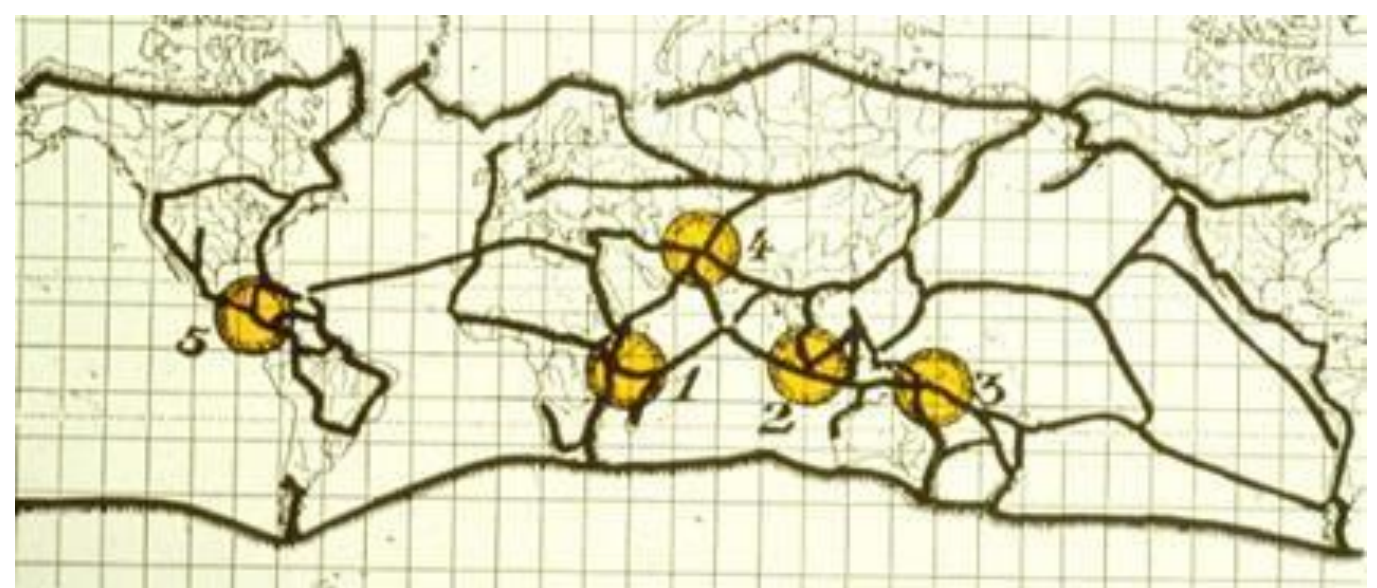

Fonte: Modificado de Croizat (1958).

A obtenção dos traços generalizados estaria inserida no que o biólogo evolutivo e biogeógrafo argentino-mexicano Juan José Morrone (1962-) denominou de homologia biogeográfica primária, representando o primeiro passo na recuperação de padrões de distribuição, através de geração de hipóteses (MORRONE, 2004). Além disso, os trabalhos de Morrone passaram a incorporar a ideia de que os padrões de distribuição deveriam ser identificados com base numa regionalização biogeográfica, tendo inclusive proposto uma detalhada subdivisão da região Neotropical dentro de uma classificação hierárquica em três sub-regiões, duas zonas de transição, sete domínios e 53 províncias e distritos (Morrone, 2014).

Morrone foi, e continua sendo, um dos grandes defensores e divulgadores do método de Croizat, com dezenas de trabalhos empregando a análise pan-biogeográfica de traços um método útil para identificar biotas e um primeiro passo para a realização de uma análise biogeográfica evolutiva (veja MORRONE, 2015, para uma revisão e um histórico detalhados da Pan-biogeografia). Ele e, na época, sua aluna de doutorado Amparo Echeverry Gómez (ECHEVERRY \& MORRONE, 2010) propuseram uma nova e interessante utilização da mesma, 
aplicando a Análise de Parcimônia de Endemismos, a conhecida PAE, como uma ferramenta pan-biogeográfica. Enquanto na PAE, uma matriz de dados é construída com os táxons versus as unidades geográficas operacionais (e.g., áreas ou quadrículas), no método "PAE + Pan", os táxons passam a ser representados por seus traços individuais. Estes segmentos ao conectarem dois pontos no espaço, na verdade, desenham a projeção espaço-temporal da distribuição real e podem indicar a distribuição potencial. Além disso, a aplicação da "PAE + Pan", ao invés dos já tradicionalmente utilizados "árvores de distância mínima", "matrizes de conectividade e incidência" ou "compatibilidade de traços", aparentemente é mais eficiente para encontrar os traços generalizados (CARVALHO \& ALMEIDA, 2011; FERRARI et al. 2013; MORRONE, 2014).

Em meados da década de 1970, no auge da Sistemática Filogenética de Willi Hennig e da Teoria da Tectônica de Placas de William Jason Morgan (1935-), três conceituados pesquisadores do American Museum of Natural History (AMNH), Gareth Nelson (1937-), Donn Eric Rosen (1929-1986) e Norman Platnick (1951-2020) abraçaram a ideia de associar os princípios de ambas (NELSON \& PLATNICK, 1980) com a Pan-biogeografia de Léon Croizat. Esta proposta causaria uma revolução na Biogeografia, que passaria a integrar definitivamente, através de uma metodologia explícita, a história dos táxons e da Terra, conforme a metáfora de Croizat. A nova escola foi batizada de Biogeografia de Vicariância ou Cladística e fundada pelo artigo "Centers of origin and related concepts", publicado em 1974 na renomada revista Systematic Zoology, por Croizat, Nelson e Rosen. Surpreendentemente para os pesquisadores norte-americanos, mas talvez nem tanto para quem conhecia suas ideias, Croizat não reconheceu a coautoria do artigo, deixando isso claro numa publicação de 1982. Aqui, cabe destaque a um trecho bastante elucidativo deste artigo e que ilustra muito bem toda a controvérsia: "Naturally, I deeply resent that my lifework, Panbiogeography, has been dragged in with Hennigism to the very extent of publicly losing its identity under the improper designation of 'Vicariance Biogeography.' There can be here no question of opinion, personal vanity and antagonism. The fact plainly is that an enormous amount of confusion now, and for long years, alas, to come, will be imputable to Gareth Nelson for having overambitiously pretended to 'fruitfully' synthesize - imagine that - Hennig with Croizat, hoping thus to achieve for himself the highest possible mark in historic and scientific biogeography." Croizat defendia a sua pan-biogeografia como um método comparativo, enquanto a Biogeografia de Vicariância incorporava uma teoria. 
Croizat e sua pan-biogeografia sofreram muitas críticas técnicas e pessoais, chegando ao ápice de ser reconhecido como "enigmático", "polêmico", "lunático" e "não científico". Muitas vezes, torna-se difícil dissociar a crítica ao método e ao próprio autor. Este embate era tão intenso nos anos 1970 e 1980, que Croizat, na já referida publicação de 1982, finalizou o texto com um detalhado e irônico parágrafo sobre sua vida pessoal e profissional (Croizat, 1982, pág. 302-303).

Aparentemente, durante toda a segunda metade do século XX e a primeira década do século XXI, houve uma dicotomia entre os dispersionistas versus vicariancistas. Alguns autores aceitavam apenas a vicariância como processo explanatório de padrões de distribuição, enquanto outros utilizavam apenas a dispersão. Para outros autores, entretanto, ambos os processos deveriam ser considerados, face aos padrões encontrados, ou seja, alguns padrões poderiam ser melhor compreendidos por vicariância, enquanto outros, por dispersão. Em virtude desse possível modelo dispersão-vicariância, o entomólogo sueco Fredrik Ronquist (1962 -) propôs um método que ficou conhecido como DIVA, uma abreviatura para Dispersal-Vicariance Analysis (RONQUIST, 1997). DIVA é um método de parcimônia que considera todos os possíveis eventos necessários pra explicar os padrões obtidos, ou seja, vicariância, dispersão, extinção e duplicação (reticulação). E Juan Morrone sugeriu um modelo de dispersão-vicariância, com a datação das linhagens e identificação dos chamados "cenocrons", que representariam um conjunto de táxons coexistindo numa biota.

Curiosamente, a partir da segunda década do século XXI, a rivalidade "dispersão contra vicariância" retornou sob a denominação de neodispersionismo, termo criado pelo biogeógrafo neozelandês Michael Heads (1957-). Dentro desta nova-velha óptica, todos os padrões de distribuição seriam modernos, e somente compreendidos à luz da dispersão quer dizer, evidências geológicas contraditórias não seriam consideradas. Na verdade, neodispersionismo seria mais aplicado para explicar os padrões de grupos atuais, dentro do arcabouço do Tree thinking e datando as linhagens com base no relógio molecular. Heads também sugeriu a utilização de filogenias moleculares para interpretar os padrões de distribuição obtidos com análise de traços. Malte C. Ebach e Davis M. Williams forneceram um detalhado histórico sobre o dispersionismo e uma interessante discussão sobre o novo dispersionismo (WILLIANS \& EBACH, 2008; EBACH \& WILLIANS, 2016). 


\section{CONCLUSÕES}

A partir do século XVIII, ideias dispersionistas eram a principal explicação para a presença de organismos em determinadas regiões da terra. Léon Croizat foi responsável por criar uma nova vertente para a biogeografia, destacando a importância do espaço, tempo e forma, o que é relevante para o entendimento da distribuição histórica das biotas. Os trabalhos de León Croizat, de John Grehan, Michael Heads e Juan José Morrone, aliados a programas de computador permitiram que a biogeografia se tornasse analítica e não mais narrativa como, por exemplo, a Análise de Traços, a PAE e a Biogeografia Cladística. Estes e outros métodos permitiram um melhor entendimento de processos que influenciam a distribuição das biotas.

\section{AGRADECIMENTOS}

A autora Valéria Gallo agradece ao Conselho Nacional de Desenvolvimento Científico e Tecnológico (CNPq) pela bolsa de produtividade em pesquisa e à Fundação Carlos Chagas Filho de Amparo à Pesquisa do Estado do Rio de Janeiro (FAPERJ/UERJ) pela bolsa do Programa de incentivo à Produção Científica Técnica e Artística (PROCIÊNCIA).

\section{REFERÊNCIAS}

BUCH, J.C L. Physicalische Beschreibung der Canarischen Inseln. 8 vols. 1825.

BUENO, A; LLORENTE J. Las sintesis biogeográfica de Charles Lyell. 295-319 In: LLORENTE, J;; RUIZ, R.; ZAMUDIO, G \& NOGUERA, R (Com). 2008. Fundamentos históricos de La Biología. Universidade Nacional Autónoma de México. 640p, 2008.

BUFFON, G. Storia Naturale di Buffon: Teoria della Terra. Tomo 1. Piaccenza: Torchi del Maino, 1812.

CANDOLLE, A. P. de 1820. Géographie botanique. In: Dictionnaire des Sciences Naturelles. Estrasburgoparis, F.G. Levrault, 13, pp. 359-422.

CARVALHO, C. J; ALMEIDA, E. Biogeografia da América do Sul. São Paulo, Editora Roca, 2011.

CARVALHO, D. Geographia do Brasil. Rio de Janeiro, Emp. Photo-Machanica do Brasil, 1913. 
COX, C. From generalized tracks to ocean basins - How useful is Panbiogeography? Journal of Biogeography, 25: 813-828, 1998.

COX, C; MOORE, P. Biogeografia: uma abordagem ecológica e evolucionária. $7^{\circ}$ edição. Editora Gen, LTC, Rio de Janeiro, 398p, 2009.

CRAW, R; GREHAN, J; HEADS, M. Panbiogeography: tracking the history of life. Oxford: Oxford University Press. 229p, 1999.

CROIZAT, L. 1958. Panbiogeography 3 Vols. Caracas: publicado pelo autor.

CROIZAT, L. Space, time and form: the biological synthesis.Caracas: Editado pelo autor, 1964

CROIZAT, L. Hennig (1966) entre Rosa (1918) y Lovtrup (1977): medio siglo de sistematica filogenetica. Boletiin de la Academia de Ciencias Fisicas, Matematicas y Naturales (Caracas), 38: 59-147, 1978.

CROIZAT, L. Vicariance/Vicariism, Panbiogeography, "Vicariance Biogeography," Etc.: A Clarification. Systematic Zoology, 31(3): 291-304, 1982

CROIZAT, L; NELSON, G; ROSEN, D. Centers of origin and related concepts. Systematic Zoology, 23(2): 265-287, 1974.

CRUZ, C. M. G. C. Leopold von Buch (1774-1853, las Islas Canarias y origen de La teoria de los Crateres de Elevacíon. ILUIL, 39(83):1-29,2016.

D'ORBIGNY, A. D. Paleontólogie Française. Description zoologique et géologique de tous les animaux mollusques et rayonnes fossiles de france. Paris, 400p, 1850.

DANA, J. D. Coral and Islands Coral. Dood Meady \& Company, New York, 400p, 1879.

DARLINGTON, P. Zoogeography:the geographical distribution of animals. New York: J. Wiley and Sons, 1957.

EBACH, M; WILLIAMS, D. Dispersalism and neodispersalism. In: Williams, D., Schmitt, M. \& Wheeler, Q. (eds.) The Future of Phylogenetic Systematics: The Legacy of Willi Hennig. P. 286-328. Cambridge University Press, 2016.

ECHEVERRY, A; MORRONE, J. J. Parsimony analysis of endemicity as a panbiogeographical tool: An analysis of Caribbean plant taxa. Biological Journal of the Linnean Society, 101: 961-976, 2010.

FERRARI, A; BARÃO, K; SIMÕES, F. Quantitative panbigoeography: was congruence problem solved? Systematics and Biodivertsity, 11, 285-302, 2013.

FIGUEIREDO, F. J; ABSOLON, B. A; GALLO, V. Emilio Joaquim da Silva Maia (1808-1859) e o seu ensaio sobre 
'Geographia Zoológica'. Filosofia e História da Biologia, 12(2): 251-274, 2017.

FIGUEIRÓ, A. Biogeografia. Dinâmica transformacões e formações da natureza. Editora Oficina de textos, São Paulo, 2015.

GOOD, Ronald. The geography of the flowering plants. 3ed, 518p, 1964.

GREHAN, John. Evolution by law: CROIZAT's 'orthogeny' and DARWIN's 'laws of growth'. Tuatara 27: 14-19, 1984.

GREHAN Biogeography and evolution of the Galapagos: integration of the biological and geological evidence. Biological Journal of the Linnean Society, 74(3): 261-267, 2001.

HEADS, M. What is a node? Journal of Biogeography, 31, 1883-1891, 2004.

HENNIG, W. Elementos de una sistemática filogenética. Buenos Aires; EDUEBA. 353p. 1968.

HERNANDEZ, A; BOUSQUETS, J.L. El centro de origen en la Biogeografia: Historia de um concepto. pp. 1-33. In: BOUSQUETS, Jorge Llorente (Ed.) - Historia de la Biogeografia: Centros de Origen y vicarianza. Mexico: Universidad Autonoma de Mexico, 1991.

HOLT, B; LESSARD, J; BORREGARD, M; FRITZ, S; ARAÚJO, M; DIMITRO, D. An update of Wallace's Zoogeographic regions of the World. Science, 339 (6115): 74-78, 2013.

HUMBOLDT, A. F. Von. Distributione geographica plantarum, 266p, 1817.

IHERING, H. von. The history of the Neotropical region. Science 12: 857-864, 1900.

IHERING, Rodolpho von. Atlas da fauna do Brasil. São Paulo: Melhoramentos, 1916.

LOSOS, J; RICKEFELS, R. E. The Theory of Island Biogeography Revisited. Princeton University Press, 250p, 2009.

MACARTHUR, R; WILSON, E. The theory of island biogeography. New Jersey: Princeton University Press, 1967.

MATTHEW, W. D. Climate and evolution. Annals of the New York Academy of Sciences 24: 171-318, 1915.

MELLO LEITÃO, C. F. de. Zoogeographia do Brasil. Companhia Editora Nacional, São Paulo, 1947.

MORRONE, J.J. Homología biogeográfica: Las coordenadas espaciales de la vida. México; UNAM. 199p, 2004.

MORRONE, J.J. Biogeogrpahical regionalisation of Neotropical region. Zootaxa, 3782 (1): 20-40, 2014.

MORRONE, J.J. Track analysis beyond panbiogeography. Journal of Biogeography, 42: 413-425, 2015. 
MORRONE, J. J; CRISCI, J. Panbiogeografía y biogeografía cladística: paradigmas actuales de la biogeografía histórica. Ciencias, 6: 87-97, 1992.

NELSON, G; PLATNICK, N. Systematic and biogeography: cladistics and vicariance. New York: Columbia University Press, 1980.

PAGE, Roderic. Graphs and generalized tracks: Quantifying Croizat's panbiogeography: Systematic Zoology 36: $1-17,1987$.

PARENTI, L; EBACH, M. Comparative Biogeography: Discovering and classifying biogeographical patterns of a dynamic Earth. Berkeley: University of California Press, 2009.

POSADAS, P; CRISCI, J; KATINAS, L. Historical Biogeography: A review of its basic concepts and critical issues. Journal of Arid Environments 66(2006): 389-403, 2006.

RONQUIST, F. Dispersal-Vicariance analysis a new approach to the quantification of Historical Biogeography. Systematic Biology, 46(1): 195-203, 1997.

ROSA, D. L'Ologénèse: nouvelle théorie de l'évolution et de la distribution géographique. Paris: Félix Alcan. 368p, 1931.

SCLATER, Philippe Louis. On the general geographical distribution of the members of the class Aves. J. Linn. Soc. (Zool.) 2: 130-145, 1858.

SCROCCHI, G. J; DOMINGUEZ, E. Introduccion a las Escuelas de Sistemática e Biogeografia. Opera Lilloana 40, Fundacion Miguel Lillo, Tucuman, 1992.

SILVA MAIA, E. J. da. Algumas ideias sobre Geographia Zoológica. Trabalhos da Sociedade Vellosiana, 1: 39$41,1851$.

SILVA MAIA, E. J. da. Esboço histórico do Museu Nacional, servindo de introducção a trabalhos sobre as principais espécies zoológicas do mesmo estabelecimento. Trabalhos da Sociedade Vellosiana, 2: 90-99, 1852 pp. 90-99.

SLOAN, P. The Buffon-Linnaeus controversy. 271-294. In; LLorente, Jorge; ZAMUDIO, Graciela, NOGUERA, Ricardo. Fundamentos históricos de La Biología. Universidade Nacional Autónoma de México. 640p, 2008.

SIMPSON, G. G. Mammals and land bridges. Journal of the Washington Academy of Sciences, 30(4): 137-163, 1940

SIMPSON, G. G. The geography of Evolution. Philadelphia-New York: Chilton Books, 1965.

SNIDER-PELLEGRINI, A. La création et ses mysteres dévoilés. Librarie Anne Franck, Paris, 538p, 1858. 
SPELLEBERG, I; SAWYER. J. An introduction to applied biogeography. Cambridge: Cambridge University Press. 243p, 2000.

TOMECEK, S. Plate tectonics. Library of Congress cataloging, United States, 102p, 2009.

WAGNER, M. F. Der Kaucasus das londen der Kosaken. 400p, 1850.

WALLACE, A. R. The geographical distribution of animals. 2 vols. London: Macmillan, 1876.

WHITTAKER, R; FERNANDEZ-PALACIOS, J. de. Island Biogeography. Ecology, evolution and Conservation. 1ed. Oxford University Press, 383p, 2007.

WILLIAMS, D; EBACH, M. Fundations of Systematics and Biogeography. NewYork: Springer. 309p, 2008.

ZIMMERMANN, E. A. W. von. Specimen Zoologiae Geographicae, quadrupedum domicilia et migrations sistens. Lugni, Batavorum, Leiden, 736p, 1777.

\section{(c)) $\mathrm{EY}$}

Este trabalho está licenciado com uma Licença Creative Commons - Atribuição 4.0 Internacional. 